\title{
Diagnóstico de gestão de resíduos sólidos de hortaliças em agroindústrias do Municipio de lbiúna - SP
}

\author{
Diagnostic management of solid waste vegetables in agroindustry of the \\ municipality Ibiuna - SP
}

\author{
Francisco Rafael Martins Soto ${ }^{(*)}$ \\ Claudemir Junior Jacob ${ }^{2}$
}

\section{Resumo}

Objetivou-se neste trabalho o diagnóstico de gestão de resíduos sólidos de hortaliças (RSH) em agroindústrias do Municipio de Ibiúna-SP. O trabalho foi realizado em 25 estabelecimentos. Para a coleta de informações a respeito do sistema de gestão de RSH foi elaborado um banco de dados eletrônico. Foram feitas questões na qual versavam sobre a existência ou não de tratamento de RSH, licenciamento e certificação ambiental, outorga de uso e lançamento de efluentes e geração ou não de produtos de valor agregado com pesos distintos de 1 a 10. As agroindústrias foram classificadas em: insatisfatórias, satisfatórias com restrição e satisfatórias. O questionário foi aplicado por meio de entrevistas. Foram classificadas como insatisfatórias $60 \%$ das agroindústrias, com valor médio de 37,30 pontos, e satisfatórias com restrição, $36 \%$, com valor médio de 65 pontos. Somente uma foi considerada como satisfatória com 94 pontos. Houve uma baixa prática de tratamento de RSH de forma satisfatória. Ações como compras ecoeficientes, seleção de fornecedores por prática de gestão ambiental e certificação ambiental estavam ausentes ou realizadas de forma insatisfatória pela maioria das empresas. Concluiu-se que das agroindústrias investigadas, $96 \%$ foram consideradas potencialmente geradoras de riscos ambientais.

Palavras chave: alimento; meio ambiente; resíduo, tratamento.

1 Dr.; Epidemiologia Experimental Aplicada Às Zoonoses; Universidade de São Paulo, USP, Brasil revisor dos periódicos Reproduction in Domestic Animals (Alemanha), Vaccine (Reino Unido), Homeopathy (Inglaterra), Perspectives in Agriculture, Veterinary Science, Nutrition and Natural Resources (Reino Unido), Journal of Cell and Animal Biology (India), American Journal of Environmental Sciences (Estados Unidos), Ciência e Tecnologia de Alimentos, Revista Brasileira de Zootecnia, Brazilian Journal of Microbiology, Revista Veterinária e Zootecnia, Arquivos do Instituto Biológico, Revista Brasileira de Saúde e Produção Animal, Scientia Vitae, Brazilian Journal of Veterinary Research and Animal Science, Revista de Educação Continuada do Conselho Regional de Medicina Veterinária e Zootecnia, Revista Brasileira de Iniciação Cientifica, Research in Biological Sciences, Revista em Agronegócio e Meio Ambiente e Revista Sinergia; Endereço: Instituto Federal de Educação, Ciência e Tecnologia- Campus São Roque. Rodovia Prefeito Quintino de Lima, 2100, Goianã. CEP: 18136-540 - Sao Roque, SP - Brasil; E-Mail: chicosoto34@gmail.com $\left.{ }^{*}\right)$ Autor para correspondências

2 Graduado em Tecnologia em Gestão Ambiental; Instituto Federal de São Paulo; Autônomo; Endereço:Rodovia Prefeito Quintino de Lima, 2100, Bairro Paisagem Colonial, CEP 18.136-540, São Roque, SP E-Mail: juniorjacob1994@yahoo. com.br 


\section{Abstract}

The aim of this work the diagnosis of solid waste vegetable management (SWV) in agro-industries of the Municipality of Ibiúna-SP. The study was conducted in 25 establishments. To collect information about SWV management system was developed an electronic database. It was drawn up in which questions were about whether or not treatment SWV, licensing and environmental certification, use of grant and sewage discharge and generation or non-value-added products with different weights from one to 10 . The agro-industries were classified in: unsatisfactory, satisfactory with restraint and satisfactory. The questionnaire was applied through interviews. They were classified as unsatisfactory $60 \%$ of agro-industries, with an average of 37.30 points, and satisfying with restriction, $36 \%$, with an average of 65 points. Only one was considered satisfactory with 94 points. There was a low practice treatment satisfactorily SWV. Actions such as eco-efficient purchasing, vendor selection practice for environmental management and environmental certification were absent or performed unsatisfactorily by most companies. It was concluded that the investigated agricultural industries, $96 \%$ were considered potentially generating environmental risks.

Key words: food; environment; waste; treatment.

\section{Introdução}

Segundo a ISO 14.001, gestão de resíduos sólidos é uma estrutura desenvolvida para que uma organização possa consistentemente controlar seus impactos significativos sobre o meio ambiente e melhorar continuamente as operações e negócios.

Um dos principais entraves ao desenvolvimento da agroindústria de processamento mínimo de hortaliças em diversas partes do mundo está associado à significativa quantidade de resíduos sólidos de hortaliças (RSH) que são gerados pela atividade, com uma boa parcela começando a ser produzida no sistema produtivo, relacionado principalmente com a ausência ou baixa aplicação de boas praticas de produção (OLIVEIRA et al., 2009).

A má gestão de RSH gera desdobramentos que causam prejuízo para o meio ambiente, para a saúde publica e a sociedade em geral (GONÇALVES et al., 2011).

A água contaminada por matéria fecal de origem humana, por exemplo, utilizada na irrigação de hortas, contribui para a contaminação das folhas das hortaliças por bactérias e ovos de parasitas intestinais (FALAVIGNA, et al., 2005), o que acelera a sua decomposição e aumenta a produção de $\mathrm{RSH}$, além de implicações negativas para a saúde pública.

A maior parte dos RSH é disposta no ambiente ou utilizada na alimentação animal, sem qualquer tratamento o que gera restrições legais para tal prática (MIGUEL et al., 2008). A manutenção de RSH na superfície do solo dificulta a ação microbiana em virtude do menor contato com o solo, resultando numa decomposição mais lenta. Com isso, e também com o constante aporte de resíduos, é possível ocorrer produção contínua de compostos orgânicos de baixa massa molecular, sendo seu efeito negativo na fertilidade (PAVINATO, ROSOLEM, 2008). Ademais, RSH deixados na superfície do solo podem também diminuir a acidez e reduzir o efeito do alumínio, prejudicando a qualidade do solo (AMARAL et. al., 2000). 
A gestão eficiente de RSH em uma agroindústria deve possibilitar oportunidades mercadológicas e sociais interessantes para a empresa, como melhoria da sua imagem e uma percepção positiva do consumidor dos produtos que ela produz, resultando em mais vendas, além da promoção de um meio ambiente saudável e da saúde pública (SANTOS et al., 2015). Entretanto, há uma carência de investigações que permitem traçar um diagnóstico do que está sendo feito em relação ao gerenciamento de RSH nas regiões produtoras e processadoras de hortaliças.

Com base neste cenário, este trabalho teve por objetivo realizar o diagnóstico de gestão de $\mathrm{RSH}$ em agroindústrias do Municipio de Ibiúna-SP.

\section{Materiais e Métodos}

O trabalho foi realizado em 25 agroindústrias processadoras de hortaliças do Municipio de Ibiúna- SP, escolhidas aleatoriamente no período compreendido entre 01 de agosto a 01 de novembro de 2015. Para a coleta de informações a respeito da gestão de resíduos sólidos de hortaliças (GRSH) nas empresas avaliadas e seu posterior armazenamento, foi elaborado um banco de dados eletrônico com a utilização do programa Google drive ${ }^{\circledR}$ (2013). Neste banco de dados foi inserido um questionário desenvolvido conforme metodologia proposta por Carvalho et al. (2015) e adaptada para esta investigação a fim de obter informações a respeito da GRSH nas respectivas agroindústrias.

Foram elaboradas 13 questões fechadas e três abertas para que as mesmas pudessem abranger todos os itens possíveis de estarem presentes em uma GRSH e assim classificar os respectivos quesitos, nas quais foram: legislação, gestão, tratamento de RSH e retorno financeiro do RSH. Para o item legislação as perguntas foram: a existência ou não de outorga de uso e captação de água e lançamento de efluentes; alvará sanitário e de funcionamento municipal atualizado; licença ambiental emitida por órgão estadual e ou federal; se as atividades estavam sendo praticadas dentro dos padrões ambientais e qual era a destinação final dos RSH. No item gestão, as perguntas foram as seguintes: se eram realizadas ações para conscientizar e capacitar os funcionários com relações ambientais e sanitárias; se havia na empresa a prática de compras ecoeficientes; presença ou não de consultoria ambiental; algum tipo de seleção de fornecedores por prática de gestão ambiental; se eram realizadas ações para mitigar os impactos ambientais gerados pela agroindústria e se a mesma possuía alguma certificação ambiental. Para o quesito tratamento, as perguntas foram: a prática ou não de algum tratamento do RSH, e se afirmativo, qual era; se havia algum tipo de tratamento para a reutilização de água utilizada nos processos de irrigação e lavagem das hortaliças e a prática ou não da coleta seletiva. Em retorno financeiro as perguntas foram: se no processo de coleta e destinação final do RSH havia algum tipo de agregação de valor monetário e se existia algum tipo de retorno com as realizações de seus tratamentos internos para a agroindústria.

Para cada questão foram atribuídos pesos distintos de 1 a 10 (SOTO et al.,2006), de acordo com a importância e o impacto ambiental de cada item realizado ou não pela agroindústria, e variando de 2 (para a presença de produto com valor agregado resultante de algum processo) a 10 (atribuído aos itens considerados fundamentais para uma eficiente GRH). As agroindústrias foram classificadas em três categorias, tanto na somatória de todos os itens avaliados, como também de forma individual de cada quesito presente ou não na GRSH em: insatisfatórias com 
pontuação abaixo de 50 pontos, satisfatórias com restrição, entre 51 e 70 pontos e satisfatórias com pontuação acima ou igual a 70 pontos (SOTO et al., 2006).

O questionário foi aplicado por meio de entrevistas diretamente com o gerente e ou proprietário das agroindústrias investigadas e os resultados foram analisados com a utilização do software Br Office Calc (2014).

\section{Resultados e Discussão}

$\mathrm{Na}$ Tabela 1, estão apresentados os resultados totais obtidos em relação à pontuação nos sistemas de GRSH das 25 agroindústrias investigadas.

\section{Tabela 1- Classificação das agroindústrias do Município de Ibiúna- $\mathrm{SP}$, em relação ao sistema de gestão de resíduos sólidos de hortaliças empregado e as respectivas porcentagens, pontuações totais e médias obtidas}

\begin{tabular}{cccccc}
\hline Classificação & $\begin{array}{c}\mathbf{N}^{\circ} \\
\text { agroindústrias }\end{array}$ & $\mathbf{\%}$ & MEP & MAP & PM \\
\hline Insatisfatórias & 15 & 60 & 0 (zero) & 46 & 37,3 \\
Satisfatórias com restrição & 09 & 36 & 57 & 68 & 65 \\
Satisfatórias & 01 & 04 & 94 & 94 & 94 \\
Total & 25 & 100 & 50,3 & 69,3 & 65,4 \\
& & & & \\
$N^{\circ}$ - número; \% - porcentagem; MEP- menor pontuação; MAP- maior pontuação, PM- pontuação média.
\end{tabular}

Foram classificadas como insatisfatórias 15 (60\%) agroindústrias do total de 25 avaliadas, com valor médio de 37,30 pontos, e satisfatórias com restrição, nove, (36\%), com valor médio de 65 pontos (Tabela1). Estes dois itens classificatórios juntos representaram $96 \%$ de agroindústrias potencialmente geradoras de riscos ambientais, relacionados principalmente a disposição e destino inadequado dos RSH no meio ambiente. Considerando as menores (zero) e maiores (46) pontuações nas agroindústrias classificadas como insatisfatórias, foram encontrados valores médios de 37,30 pontos, aquém do mínimo necessário para um GRSH que ofereça minimização de riscos ao meio ambiente. Apesar de estar em vigor desde agosto de 2010, a Política Nacional de Resíduos Sólidos, observa-se que ainda não há um empenho nas agroindústrias processadoras de hortaliças na gestão de seus resíduos (Santos et al., 2017). A maior pontuação média, obtida nas três classificações, apresentou valor de 69,3 pontos, considerado satisfatório com restrição (Tabela 1).

Das agroindústrias consideradas como satisfatórias, somente uma, ou 4\%, atingiu esta classificação com 94 pontos, valor considerado baixo quando se considera 25 empresas investigadas. Deste resultado, observa-se que a GRSH está colocada em segundo ou terceiro plano na lista de prioridades das agroindústrias, resultado semelhante foi relatado por Fagundes et al., (2012), em um trabalho onde foi avaliada a gestão de resíduos sólidos de frutas e hortaliças gerados no entreposto terminal de São Paulo da Companhia de Entrepostos e Armazéns Gerais de São Paulo.

$\mathrm{Na}$ Tabela 2 estão apresentados os resultados obtidos em relação a classificação por questão relacionada ao sistema de GRSH. 


\section{Tabela 2- Resultados obtidos em relação às 25 agroindústrias investigadas e a respectiva classificação por questão relacionada ao sistema de gestão de resíduos sólidos de hortaliças. Valores expressos numericamente e em porcentagem (\%)}

\begin{tabular}{|c|c|c|c|c|}
\hline Questão & $\mathrm{AS}$ & IS & SR & SA \\
\hline Existência de outorga & $\begin{array}{c}6 \\
(24 \%) \\
\end{array}$ & $\begin{array}{c}4 \\
(16 \%) \\
\end{array}$ & $\begin{array}{c}00 \\
\text { (zero) } \\
\end{array}$ & $\begin{array}{r}15 \\
(60 \%) \\
\end{array}$ \\
\hline Alvará sanitário e de funcionamento & $\begin{array}{c}2 \\
(8 \%) \\
\end{array}$ & $\begin{array}{c}00 \\
\text { (zero) } \\
\end{array}$ & $\begin{array}{c}00 \\
\text { (zero) } \\
\end{array}$ & $\begin{array}{r}23 \\
(92 \%) \\
\end{array}$ \\
\hline Licença ambiental & $\begin{array}{c}7 \\
(28 \%)\end{array}$ & $\begin{array}{c}10 \\
(40 \%)\end{array}$ & $\begin{array}{c}00 \\
\text { (zero) }\end{array}$ & $\begin{array}{c}8 \\
(32 \%)\end{array}$ \\
\hline Atividades praticadas dentro dos padrões ambientais & $\begin{array}{c}00 \\
\text { (zero) }\end{array}$ & $\begin{array}{c}16 \\
(64 \%)\end{array}$ & $\begin{array}{c}00 \\
\text { (zero) } \\
\end{array}$ & $\begin{array}{r}9 \\
(36 \%) \\
\end{array}$ \\
\hline Destinação final dos resíduos & $\begin{array}{c}00 \\
\text { (zero) } \\
\end{array}$ & $\begin{array}{c}25 \\
(100 \%) \\
\end{array}$ & $\begin{array}{c}00 \\
\text { (zero) } \\
\end{array}$ & $\begin{array}{c}00 \\
\text { (zero) } \\
\end{array}$ \\
\hline Ações para capacitar os funcionários & $\begin{array}{c}7 \\
(28 \%)\end{array}$ & $\begin{array}{c}5 \\
(20 \%)\end{array}$ & $\begin{array}{c}00 \\
\text { (zero) }\end{array}$ & $\begin{array}{r}13 \\
(52 \%)\end{array}$ \\
\hline Prática de compras ecoeficientes & $\begin{array}{c}00 \\
\text { (zero) }\end{array}$ & $\begin{array}{c}15 \\
(60 \%)\end{array}$ & $\begin{array}{c}00 \\
\text { (zero) } \\
\end{array}$ & $\begin{array}{r}10 \\
(40 \%) \\
\end{array}$ \\
\hline Consultoria ambiental & $\begin{array}{c}7 \\
(28 \%) \\
\end{array}$ & $\begin{array}{c}5 \\
(20 \%) \\
\end{array}$ & $\begin{array}{c}00 \\
\text { (zero) } \\
\end{array}$ & $\begin{array}{r}13 \\
(52 \%) \\
\end{array}$ \\
\hline Seleção de fornecedores por prática de gestão ambiental & $\begin{array}{c}00 \\
\text { (zero) } \\
\end{array}$ & $\begin{array}{c}20 \\
(80 \%) \\
\end{array}$ & $\begin{array}{c}00 \\
\text { (zero) } \\
\end{array}$ & $\begin{array}{c}5 \\
(20 \%) \\
\end{array}$ \\
\hline Ações para mitigar os impactos ambientais & $\begin{array}{c}7 \\
(28 \%) \\
\end{array}$ & $\begin{array}{c}5 \\
(20 \%) \\
\end{array}$ & $\begin{array}{c}00 \\
\text { (zero) } \\
\end{array}$ & $\begin{array}{r}13 \\
(52 \%) \\
\end{array}$ \\
\hline Certificação ambiental & $\begin{array}{c}5 \\
(20 \%) \\
\end{array}$ & $\begin{array}{c}18 \\
(72 \%) \\
\end{array}$ & $\begin{array}{c}00 \\
\text { (zero) } \\
\end{array}$ & $\begin{array}{c}2 \\
(8 \%) \\
\end{array}$ \\
\hline Prática de tratamento do resíduo & $\begin{array}{c}6 \\
(24 \%) \\
\end{array}$ & $\begin{array}{c}8 \\
(32 \%) \\
\end{array}$ & $\begin{array}{c}5 \\
(20 \%) \\
\end{array}$ & $\begin{array}{r}6 \\
(24 \%) \\
\end{array}$ \\
\hline Tratamento para a reutilização de água & $\begin{array}{c}5 \\
(20 \%)\end{array}$ & $\begin{array}{c}14 \\
(56 \%)\end{array}$ & $\begin{array}{c}2 \\
(8 \%)\end{array}$ & $\begin{array}{c}4 \\
(16 \%)\end{array}$ \\
\hline Prática da coleta seletiva & $\begin{array}{c}00 \\
\text { (zero) } \\
\end{array}$ & $\begin{array}{c}18 \\
(72 \%) \\
\end{array}$ & $\begin{array}{c}7 \\
(28 \%) \\
\end{array}$ & $\begin{array}{r}00 \\
\text { (zero) } \\
\end{array}$ \\
\hline Agregação de valor monetário no tratamento do resíduo & $\begin{array}{c}6 \\
(24 \%) \\
\end{array}$ & $\begin{array}{c}18 \\
(72 \%) \\
\end{array}$ & $\begin{array}{c}00 \\
\text { (zero) } \\
\end{array}$ & $\begin{array}{r}1 \\
(4 \%) \\
\end{array}$ \\
\hline $\begin{array}{l}\text { Retorno financeiro com as realizações de seus tratamentos } \\
\text { internos }\end{array}$ & $\begin{array}{c}6 \\
(24 \%)\end{array}$ & $\begin{array}{c}8 \\
(32 \%)\end{array}$ & $\begin{array}{r}00 \\
\text { (zero) }\end{array}$ & $\begin{array}{c}11 \\
(44 \%)\end{array}$ \\
\hline
\end{tabular}

\footnotetext{
AS-Auséncia, IN-Insatisfatória SR-Satisfatória com restrição, SA- Satisfatória
}

Infere-se como dados importantes que apenas $60 \%$ das agroindústrias possuíam outorga, entretanto não se investigou se as $40 \%$ que não possuíam outorga, haviam iniciado o pedido para adquirir o documento. Em 32\% das agroindústrias avaliadas não possuíam licença ambiental, o que evidenciou a necessidade por parte dos órgãos governamentais do Estado de São Paulo, no desenvolvimento de legislação mais rigorosa e especifica para esta atividade, além de maior cobertura fiscalizatória. Ademais, há de ser considerado, que estes documentos são indispensáveis para a liberação de recursos por agências bancárias e constam na lista de itens que são avaliados 
em auditorias feitas por empresas compradoras de hortaliças. Para o item alvará sanitário e de funcionamento, o resultado foi satisfatório, com 92\% (Tabela 2) das agroindústrias atendendo a este quesito, demostrando assim um descompasso entre cumprimento das normas sanitárias e as ambientais, pois somente $36 \%$ responderam cumprir as normas ambientais de forma satisfatória.

Em relação a prática de tratamento de RSH, somando-se a três classificações, 76\% das agroindústrias, estiveram na faixa de ausência, insatisfatória e satisfatória com restrição. Para o destino final dos RSH, 100\% foram consideradas insatisfatórias, o que novamente mostra a incapacidade e a baixa preocupação das empresas investigadas em atender plenamente a estes quesitos. A forma mais utilizada respondida pela maioria dos entrevistados (32\%) foi o método de uso dos RSH no solo in natura, na qual não é adequado, devido a produção elevada de chorume que pode contaminar o lençol freático e corpos receptores (ARAÚJO et al., 2015). Tal prática também não agrega valor monetário aos RSH, o que foi respondido por $96 \%$ dos entrevistados, na qual disseram não terem retorno financeiro nos tratamentos efetuados nos RSH.Já 56\% alegaram não terem retorno financeiro de forma satisfatória com as realizações de seus tratamentos internos, envolvendo outras etapas na GRSH (BARBOSA, CÂNDIDO, 2014), que culminará em vendas melhores de hortaliças. O conceito moderno de GRSH deve contemplar agregação de valor no seu tratamento e ampliação de rendas oriundas desta gestão (FARIAS FILHO, et al., 2013). Barros et al., (2017), por exemplo, sugeriram a utilização de RSH para a confecção de plásticos biodegradáveis, o que possibilita a geração de um produto de valor agregado e ecoefeciente.

Questões mais avançadas na GRSH como compras ecoeficientes, seleção de fornecedores por prática de gestão ambiental e certificação ambiental ainda estão distantes de uma ação efetiva pelas agroindústrias investigadas, na qual ou estão ausentes ou sendo realizadas de forma insatisfatória pelas agroindústrias (Tabela 2). Entretanto, $52 \%$ dos entrevistados responderam ter serviço de consultoria ambiental, capacitarem seus funcionários e praticarem ações para mitigar os impactos ambientais de forma satisfatória (Tabela 2). Observa-se então, com estes resultados, que há ainda uma fragmentação das agroindústrias na GRSH.

Em relação ao tratamento para a reutilização de água, 76\% dos entrevistados responderam que não o faziam, demonstrando que apesar do tema água de reuso ser relevante (SILVA et al.,2014), ainda não despertou a atenção das empresas pesquisadas. Mesma interpretação pode ser dada para a prática da coleta seletiva, onde $72 \%$ disseram pratica-la de forma insatisfatória, alegando em sua maioria falta de apoio e de infraestrutura principalmente por parte dos órgãos governamentais. Entretanto, a coleta seletiva de RSH poderia ser direcionada para a reutilização deste resíduo para a alimentação de animais e ou compostagem, envolvendo por exemplo, comunidades próximas as agroindústrias. Práticas simples e de baixo custo que dariam um destino sustentável do ponto de vista econômico, social, sanitário e ambiental para os RSH (LABEGALINI, et al., 2017)

\section{Conclusões}

Com base nos resultados obtidos e nas condições em que foi efetuado o trabalho pode se concluir que, foram classificadas como insatisfatórias $60 \%$ das agroindústrias, e satisfatórias com restrição 36\%. Das agroindústrias investigadas, $96 \%$ foram consideradas potencialmente geradoras de riscos ambientais. Houve uma baixa prática de tratamento e destino final de RSH de forma satisfatória sem geração de produtos de valor agregado. Questões mais avançadas na GRSH 
como prática de compras ecoeficientes, seleção de fornecedores por prática de gestão ambiental e certificação ambiental estavam ausentes ou estavam sendo realizadas de forma insatisfatória pela maioria das agroindústrias investigadas. Apesar da alta porcentagem de agroindústrias insatisfatórias e satisfatórias com restrição, é possível com ações simples e de baixo custo na GRSH melhorar a classificação destas empresas, principalmente no quesito tratamento e destino final dos RSH, com a prática da compostagem e do uso do RSH para alimentação de animais.

\section{Referências}

AMARAL,A. S.; ANGHINONI, V.S.I.; MEURER, E. J. Resíduos vegetais na superfície do solo afetam a acidez do solo e a eficiência do herbicida flumetsulam, Ciência Rural, Santa Maria, v.30, n.5, p.789-794, 2000.

ARAÚJO, P. C. M.; DE ARAÚJO, NATALY A. J, SILVA, D. F. Diagnóstico Preliminar do Saneamento Rural na Comunidade de Engenho Velho no Município de João Pessoa/PB. Revista Ambiental, v. 1, n. 1, p. 26-36, 2015.

BARBOSA, M. F. N.; CÂNDIDO, G. A. Práticas ambientais e suas relações com a competitividade e a sustentabilidade: um estudo de caso em empresa agroindustrial. Latin American Journal of Business Management, v. 4, n. 2, p. 58-80, 2014.

BARROS, T. T.; TOSI, M. M.; ASSIS, O. B. G. Aproveitamento de rejeitos da cadeia hortofrutícula no processamento de plásticos biodegradáveis. Revista Gestão Industrial, v. 13, n. 2, p.1- 15, 2017.

CARVALHO, B. V.; SOUSA, A. P. M.; SOTO, F. R. M. Avaliação de sistemas de gestão ambiental em granjas de suínos. Revista Ambiente \& Água, v. 10, n. 1, p. 164-171, 2015.

FAlAVIGNA, L. C.; FrEITAS, C. B. R.; MELO, G. C.; ARAÚJO, L. N. S. M.; GUILHERME, A. L. F. Qualidade de hortaliças comercializadas no noroeste do Paraná, Brasil. Parasitologia Latino Americana, v. 60, p. 144 - 149, 2005.

FAGUNDES, P.; OLIVEIRA P. R.; NACHILUK, S. K.; MONDINI, L. Aproveitamento dos resíduos gerados no entreposto terminal de São Paulo da CEAGESP. Informações Econômicas, SP, v. 42, n.3, p. 65-73, 2012.

FARIAS FILHO, M. C.; SILVA, S. F.; SILVA, R.F. Ações de Responsabilidade Socioambiental de Agroindústrias de Polpa de Açaí. REUNA, v. 18, n. 4, p. 21-36, 2013.

GONÇALVES, R. D.; MOREIRA, D. A.; ERASTO, F. A.; COSTA, R. R.; ARAUJO, A. K. Análises de qualidade das matérias-primas desprezadas oriundas da feira livre de Bananeiras-PB. Caderno Verde de Agroecologia e Desenvolvimento Sustentável, v. 1, n.1, p. 1, 2011. 
LABEGALINI, N. S.; LEITE, C. L.; ROBOREDO, D.; VALIGUZSKI, A. L.; PAULINO, F. C. Construção de uma compostagem no Lar Santa Isabel, Alta FlorestaMT. Revista Ciência em Extensão, v. 13, n.2, p. 89-96, 2017.

MIGUEL,A.C.A.; ALBERTINI, S.; BEGIATO, G.F.DIAS, J. R.P.S.; SPOTO, M.H. F. Aproveitamento agroindustrial de resíduos sólidos provenientes do melão minimamente processado. Ciência e Tecnologia de Alimentos, Campinas, v. 28, n.3, p.: 733-737, 2008.

OLIVEIRA, C. F.; UGUEN, K.; SOUSA, S. G. A. Caracterização da produção de hortaliças na região periurabana de Parintins-AM. Cadernos de Agroecologia, v. 4, n.1, p.2859-2861, 2009.

PAVINATO, P. S.; ROSOLEM, C. A. Disponibilidade de nutrientes no solo decomposição e liberação de compostos orgânicos de resíduos vegetais. Revista Brasileira de Ciência do Solo, v. 32, p. 911-920, 2008.

SANTOS, A. T. L.; HENRIQUE, N. S.; SHHLINDWEIN, J. A.; FERREIRA, E.; STACHIW, R. Aproveitamento da fração orgânica dos resíduos sólidos urbanos para produção de composto orgânico. Revista Brasileira de Ciências da Amazônia, v.3, n.1, p. 15-28, 2015.

SANTOS, J. C.; MELO, L. C. SPAZIANI, L. C. Gestão ambiental plano de gerenciamento de resíduos sólidos na CEASA-DF. Simpósio de TCC e Seminário de IC, v. 2, p. 1840, 2016.

SILVA, C. L. Z.; SILVA, F. F.; MAURÍCIO, A. A.; CAPUTO, B. A. Processamento do extrato de tomate: quantidade de água utilizada em planta industrial. Revista Acta Ambiental Catarinense, v.10, n.1-2, p. 19-28, 2014.

SOTO, F.R.M.; RISSETO, M. R.; CAZZOLA, C.P.B. Proposta e análise crítica de um protocolo de inspeção e de condições sanitárias em supermercados do município de Ibiúna- SP. Revista Brasileira de Epidemiologia, v. 9, n. 2, p. 235-241, 2006. 